DOI: $10.12957 /$ teias.2021.54019

\title{
PEDAGOGIA UNIVERSITÁRIA E PANDEMIA: novos desafios na formação docente em isolamento social
}

Gean Breda Queiros

Resumo

Refletir criticamente a pedagogia universitária em tempos de pandemia trazendo como núcleo central os novos desafios na formação docente em isolamento social. Escrita descritiva, tipo estudo teórico. Possibilita analisar a importância da construção da identidade docente para superar os desafios que o vírus também impôs ao sistema educativo. Destaque aos recentes debates sobre a formação didático-pedagógica de professores universitários e suas necessidades formativas, considerando as atuais pesquisas sobre a docência no ensino superior e os referenciais teóricos disponíveis até então, ainda não contemplam as experiências corriqueiras ocasionadas pelo surgimento da pandemia e como os professores estão exercendo as suas práticas remotamente. Em tempos de isolamento social, a Pedagogia Universitária também é convidada a se manifestar, pois dela se espera orientações para o novo formato das aulas remotas e como os professores estão reinventando e conduzindo as suas práticas pedagógicas em meio à sua formação e à formação de seus alunos.

Palavras-chave: pedagogia universitária; pandemia; didática.

\section{UNIVERSITY PEDAGOGY AND PANDEMICS: new challenges in teacher education in social isolation}

\begin{abstract}
To critically reflect university pedagogy in times of pandemic, bringing as its central core the new challenges in teacher education in social isolation. Descriptive writing, theoretical study type. It makes possible to analyze the importance of building a teacher's identity to overcome the challenges that the virus has also imposed on the educational system. Highlighting the recent debates on the didactic-pedagogical training of university professors and their training needs, considering the current research on teaching in higher education and the theoretical references available so far, they still do not contemplate the common experiences caused by the emergence of the pandemic and how the teachers are exercising their practices remotely. In times of social isolation, University Pedagogy is also invited to manifest itself, as guidance is expected for the new format of remote classes and how teachers are reinventing and conducting their pedagogical practices in the midst of their training and to the training of its students.
\end{abstract}

Keywords: university pedagogy; pandemic; didactic.

PEDAGOGÍA UNIVERSITARIA Y PANDEMIA: nuevos retos en la formación del profesorado en aislamiento social

Resumen

Reflejar críticamente sobre la pedagogía universitaria en tiempos de pandemia, teniendo como eje central los nuevos desafíos en la formación del profesorado en el aislamiento social. Escritura descriptiva, tipo estudio teórico. Permite analizar la importancia de construir una identidad docente para superar los desafíos que el virus también ha impuesto al sistema educativo. Destacando los debates recientes sobre la formación didáctico-pedagógica de los profesores universitarios y sus necesidades formativas, considerando las investigaciones actuales sobre la docencia en la educación superior y las referencias teóricas disponibles 
hasta el momento, aún no contemplan las experiencias comunes provocadas por el surgimiento de la pandemia y cómo los profesores están ejerciendo sus prácticas de forma remota. En tiempos de aislamiento social la Pedagogía Universitaria también está invitada a manifestarse, ya que espera orientación para el nuevo formato de clases a distancia y cómo los docentes están reinventando y conduciendo sus prácticas pedagógicas en medio de su formación y la formación de sus alumnos.

Palabras clave: pedagogía universitaria; pandemia; didáctica.

\section{INTRODUÇÃO}

Como novo campo de pesquisas, a Pedagogia Universitária vem se constituindo epistemologicamente sobre temas de estudos frente ao seu protagonismo enquanto área investigativa de políticas e ações institucionais voltadas para o desenvolvimento do campo acadêmico, principalmente para os docentes, ao levantar questões referentes ao processo formativo de professores universitários. As peculiaridades que constituem as modalidades de ensino na docência superior necessitam ser vestidas e revestidas constantemente de práticas pedagógicas que deem sentido à docência universitária e ao próprio fazer pedagógico, onde seu papel na formação humana e específica para a sociedade e o mundo do trabalho são indissociadas.

Em tempos de pandemia e isolamento social, a Pedagogia Universitária também é convidada a se manifestar, pois dela se espera orientações para o novo formato das aulas remotas e como os professores estão reinventando e conduzindo as suas práticas pedagógicas em meio à sua formação e à formação de seus alunos.

Pensar a docência universitária apenas como dinamizadora de um saber específico, já não supre mais as lacunas acadêmicas e do mundo do trabalho, ainda mais quando por parte de alguns profissionais do magistério superior, é percebido problemas com a falta de didática, elaboração de planos disciplinares e curriculares, processos de avaliação e desempenho, entre outros. Essas questões sempre foram levantadas e debatidas no meio acadêmico quando as aulas ocorriam em caráter presencias e estão sendo acentuadas ainda mais agora por intermédio das aulas remotas, ou seja, os desafios tanto continuam como aumentaram significativamente.

Dessa forma, o trabalho que algumas instituições de ensino superior estão desenvolvendo em favor do seu corpo docente e de si próprias está criando uma cultura conscientizadora de que a qualidade nos serviços prestados por meio dos processos de ensino e aprendizagem está diretamente relacionada às práticas pedagógicas emanadas por meio da formação de professores, eixo central da Pedagogia Universitária. O que era realizado presencialmente também está sendo conduzido remotamente.

As questões que nos chamam a atenção nessa abordagem, estão relacionadas às nossas experiências enquanto professores universitários, ao recebermos alguns diálogos de docentes dos cursos de graduação bacharelados e licenciados e dos discentes, onde os primeiros manifestam a falta de conhecimentos pedagógicos para suas ações e os alunos por sua vez, queixam-se da falta de didática de alguns professores. Nesse sentido, ao buscarmos os pressupostos da Pedagogia Universitária para refletir os argumentos expostos, compreendemos estar nela, o caminho para elucidarmos tais inquietações dos docentes e discentes.

Diante do contexto, nossas reflexões para esse estudo teórico estão ancoradas em duas categorias: a) o perfil do profissional docente bacharel e licenciado na construção da sua identidade como professor e suas implicações para/no campo do exercício da sua função no isolamento social, e b) o processo de formação de professores universitários, os desafios nele contido e as implicações do campo da didática para o seu desempenho profissional em formato remoto. 


\section{IDENTIDADE DOCENTE: REFLETINDO O DESENVOLVIMENTO PROFISSIONAL EM ISOLAMENTO SOCIAL}

O desenvolvimento profissional está associado à construção da identidade docente, seja ela, individual, coletiva e histórica de cada sujeito e da aprendizagem profissional (BOLFER, 2008). Para compreendermos as relações que constituem e reconstituem o desenvolvimento profissional docente, recorremos às reflexões de Pimenta e Anastasiou (2014) em seu livro Docência no Ensino Superior. Para as autoras, o desenvolvimento profissional docente envolve a formação inicial e continuada, articulada a um processo de valorização identitária e profissional dos professores. A identidade do professor é também profissional; ou seja, a docência constitui um campo específico de intervenção profissional na prática social.

O desenvolvimento profissional do professor é, portanto, um processo que ocorre ao longo da sua vida pessoal e profissional, pois ao abraçar a carreira do magistério o professor se compromete pessoalmente como em outras tantas profissões, a desempenhar e dedicar a uma função carregada de intencionalidades a partir da concepção do seu saber ensinar partindo para a transformação do indivíduo, no caso o aluno em meio à sociedade. É também profissional, pois o seu trabalho e o que o constitui necessita estar em constante movimento para dar conta das especificidades das informações em todos os níveis de conhecimento e espaços por onde as propagam. Concordamos assim, com o conceito de desenvolvimento profissional de Almeida (2000) que pressupõe a ideia de crescimento, de evolução, de ampliação das possibilidades de atuação dos professores. Para tanto há que se compatibilizar duas dimensões, que se manifestam como inseparáveis na prática docente: a qualificação do professor e as condições concretas em que ele atua. Destacamos também a contribuição de Melo e Campos (2019) ao afirmarem:

O desenvolvimento profissional também envolve as experiências, sejam elas espontâneas ou planejadas pelos docentes que as realizam em prol da aprendizagem dos estudantes e que contribuem para a qualidade da sua aula. $\mathrm{O}$ desenvolvimento profissional é aqui compreendido como um processo de autoformação e de interformação, ou seja, um processo a um só tempo individual e coletivo, que ocorre a partir de necessidades reais, contextualizadas no espaçotempo de sua atuação profissional. Somente nessa perspectiva poderá haver a elaboração de saberes e práticas que possibilitem aos professores desenvolveremse para melhor desempenharem sua função. Consequentemente, esse processo impactará na constituição da identidade docente, caracterizada por idiossincrasias que envolvem uma pessoa (ou uma comunidade) que a forma perante a sociedade e a si própria, por meio de sua consciência do quem é e de como se diferencia das outras (MELO; CAMPOS, 2019, p. 49-50).

Nesse sentido, a profissão docente é uma prática educativa, ou seja: como tantas outras, é uma forma de intervir na realidade social. Portanto, ela é uma prática social. "A prática educativa é um traço cultural compartilhado que tem relações com o que acontece em outros âmbitos da sociedade e de suas instituições. Portanto, pesquisar a prática impõe-se como caminho para transformação dela" (PIMENTA; ANASTASIOU, 2014, p. 179). Nessa direção, no contexto da docência universitária, "[...] constatada e reconhecida a importância do desenvolvimento profissional da profissão docente para os professores que atuam na universidade, vários caminhos vêm sendo experimentados nas últimas décadas" (PIMENTA; ANASTASIOU, 2014, p. 108). As autoras explicam que: 
Inicialmente, houve a inclusão de uma disciplina, nos cursos de pós-graduação, sobre a metodologia do ensino superior. Embora, em geral, resumida a uma duração de 60 horas em média e nem sempre desenvolvida por profissionais que dominam os saberes necessários à docência, essa iniciativa tem sido, para muitos docentes universitários, a única oportunidade de uma reflexão sistemática sobre a sala de aula, o papel docente, o ensinar e o aprender, o planejamento, a organização dos conteúdos curriculares, a metodologia, as técnicas de ensino, o processo avaliatório, o curso e a realidade social onde atuam (PIMENTA; ANASTASIOU, 2014, p. 108).

Pimenta e Anastasiou (2014) esclarecem ainda que estudos mais recentes no Brasil e no mundo apresentam ações mais efetivas para a formação docente ocorrendo em processos de profissionalização ${ }^{1}$ continuada que contemplam diversos elementos entrelaçando os vários saberes da docência como os saberes da experiência, os saberes do conhecimento e os saberes pedagógicos na busca da construção da identidade profissional. As experiências no caso brasileiro sobre a profissionalização continuada para docente do ensino superior são experiências diferenciadas, pois segundo as autoras, "[...] decorrem de um compromisso das instituições e do coletivo de seus docentes e se realizam pela identificação, estudo e encaminhamentos das necessidades da instituição e dos sujeitos envolvidos, os professores e alunos" (PIMENTA; ANASTASIOU, 2014, p. 109).

De fato, concordamos com a posição de Pimenta e Anastasiou (2014) ao afirmarem ser fundamental conhecer a realidade das instituições procedendo de um diagnóstico dos problemas presentes em suas realidades os quais serão considerados como ponto de partida da discussão coletiva da proposta a ser posta em ação, no caso, a formação inicial e contínua de professores em exercício docente no ensino superior. As autoras ainda declaram que:

No mundo contemporâneo, podem-se identificar três aspectos que impulsionam o desenvolvimento profissional do professor universitário. São eles: a transformação da sociedade, de seus valores e de suas formas de organização e trabalho; o avanço exponencial da ciência nas últimas décadas; a consolidação progressiva de uma Ciência da Educação, possibilitando a todos o acesso aos saberes elaborados no campo da Pedagogia (PIMENTA; ANASTASIOU, 2014, p. 165).

A esses aspectos, a formação contínua e o desenvolvimento profissional docente são, conforme explica Formosinho (2009), perspectivas diferentes sobre a mesma realidade, a saber: a educação permanente dos professores que associa a formação contínua a um processo de ensinoformação e; o desenvolvimento profissional docente, que a autora considera como um processo de aprendizagem-crescimento. Por sua vez, Day (2001) considera o desenvolvimento profissional docente como mudança do pensamento e da prática (e dos contextos em que ocorrem), no sentido de melhorar a qualidade das experiências de aprendizagem dos alunos e, consequentemente, proporcionar melhores resultados. Contudo o autor alerta que as decisões sobre a mudança na prática devem estar nas mãos dos professores, tal como a aprendizagem, está, em última análise, nas mãos dos alunos. Nessa direção, ao pensarmos sobre a aprendizagem docente e a sua implicação na transformação da realidade escolar, retomamos algumas questões, também

\footnotetext{
1 Termo empregado como expressão de uma posição social e ocupacional, de inserção em um tipo determinado de relações sociais de produção e de processo de trabalho (BROILO, 2004).
} 
destacadas por Flores e Simão (2005, p. 7): “[...] o que aprendem os professores (em formação e em exercício)? Como aprendem? Com quem? Em que contextos?".

Sobre o cenário dessas questões é importante considerar que se referem ao âmbito do desenvolvimento profissional docente, pois este contexto é amplo, uma vez que o professor é um ser inacabado e por isso, não se refere a momentos pontuais mas a processos contínuos, trata-se deste se desenvolver ao longo da vida como pessoa, como profissional e no exercício da sua função docente, por meio da reflexão individual e do diálogo coletivo com os pares em conjunto com toda a comunidade acadêmico-institucional.

Para tanto, é preciso reconhecer o devido investimento da instituição de ensino superior em ações formativas voltadas para o fortalecimento do desenvolvimento profissional do professor universitário, reconhecendo dentre outras demandas a necessidade de formação pedagógica desse professor, ainda mais agora em tempos de isolamento social, onde a presença física se converteu na virtualidade e os desafios permanentes se acentuaram significativamente agregando o caráter remoto das aulas.

\section{IMPLICAÇÕES DA DIDÁTICA NO DESEMPENHO PROFISSIONAL DOCENTE EM FORMATO REMOTO}

Os recentes debates sobre a formação didático-pedagógica de professores universitários e suas necessidades formativas, considerando as atuais pesquisas sobre a docência no ensino superior e os referenciais teóricos disponíveis até então, ainda não contemplaram as experiências corriqueiras ocasionadas pelo surgimento da pandemia e como os professores estão exercendo as suas práticas remotamente. É importante ressaltar que como decorrência da importância do ensino nos cursos de graduação e o frequente despreparo dos docentes para essa atividade (no contexto presencial), a formação de professores para o ensino superior vem ganhando relevância no cenário mundial. Várias pesquisas e experiências institucionais têm sido objeto de análise em congressos científicos (ALMEIDA; PIMENTA, 2011) e já é possível observar que os eventos da área da educação ao longo do ano de 2020, estão contemplando várias questões que abordam o ensino em tempos de pandemia. Contudo, podemos refletir com as informações que possuímos, no sentido de pensarmos, como pode a Didática dar conta dos embates contemporâneos que a pandemia a fez se integrar nas aulas remotas?

Em relação à Didática, estudos nas últimas três décadas evidenciam a sua natureza essencial na formação de professores sendo o ensino, uma prática social complexa, carregada de conflitos de valor e que exige opções éticas e políticas (PIMENTA; ANASTASIOU, 2014). Nesse contexto, o professor necessita de uma fundamentação para realizar satisfatoriamente o trabalho docente, em condições de criar sua própria atividade, ou seja, sua prática de ensino em situações Didáticas específicas conforme o contexto social em que ele atue (LIBÂNEO, 2013). Nesse sentido, é que estamos presenciando o modo em que os professores universitários estão dando conta de suas ações nesses tempos atuais.

Com base na reflexão de Pimenta e Almeida (2011) entendemos que o ensino é uma atividade que requer conhecimentos específicos, consolidados por meio de formação voltada especialmente para esse fim, bem como atualização constante das abordagens dos conteúdos e das novas maneiras Didáticas de ensiná-los. Nessa direção, as ideias de Pimenta (1999) fundamentam esta reflexão, quando questionam e afirmam a necessidade de a formação de professores para a prática docente, repensar seu papel formador: 
Para quê professores numa sociedade que, há muito, superou não apenas a importância destes na formação das crianças e dos jovens, mas que também é muito mais ágil e eficaz em trabalhar as informações? E então, para quê formar professores? Contrapondo-me a essa corrente de desvalorização profissional do professor e às concepções que o consideram como simples técnico reprodutor de conhecimentos e/ou monitor de programas pré-elaborados, tenho investido na formação de professores entendendo que na sociedade contemporânea cada vez se torna mais necessário o seu trabalho enquanto mediação nos processos constitutivos da cidadania dos alunos, para o que concorre a superação do fracasso e das desigualdades escolares. O que, me parece, impõe a necessidade de repensar a formação de professores (PIMENTA, 1999, p. 15).

Conforme afirma Pimenta (1999), as pesquisas sobre a prática estão anunciando novos caminhos para a formação docente. Da mesma forma, a mediação da prática coloca-se como indispensável, porém, em estreita articulação com a teoria e ancorada na reflexão, enquanto processo que busca atribuir sentido àquilo que se pratica (PIMENTA; ALMEIDA, 2011). Por isso, a docência como as demais profissões, é historicamente construída - ou seja, constituídas em determinados momentos como respostas a determinadas necessidades postas pela sociedade. Há profissões que deixaram de existir. Há outras, hoje, que são recentes. É a dinâmica social que possibilita a emergência de profissões e requer que se modifiquem internamente para responderem a novas demandas. O que provoca alterações também no preparo para o exercício profissional (PIMENTA, 1993).

Nas questões referentes ao exercício profissional, Libâneo (2013) afirma que o trabalho docente é parte integrante do processo educativo mais global pelo qual os membros da sociedade são preparados para a participação na vida social. A educação - ou seja, a prática educativa - é um fenômeno social e universal, sendo uma atividade humana necessária à existência e ao funcionamento de todas as sociedades. Dessa forma, o avançar no processo de docência e do desenvolvimento profissional, mediante a preparação pedagógica não se dará em separado de processos de desenvolvimento pessoal e institucional: este é o desafio a ser hoje, considerado na docência do ensino superior (PIMENTA; ANASTASIOU, 2014). Nesses desafios impostos por essa modalidade de ensino, Pimenta (2005) afirma que nos últimos anos tem desenvolvido o ensino de Didática nos cursos de licenciatura e realizado pesquisas sobre formação inicial e contínua de professores. É a partir dessas experiências que expõe algumas reflexões, com o desafio de colaborar para a formação de professores. Nessa perspectiva, Libâneo (2013) afirma que a Didática é uma matéria de integração: ela nutre os conhecimentos e práticas desenvolvidos nas metodologias específicas e nas outras ciências pedagógicas para formular generalizações em torno de conhecimentos e tarefas docentes comuns e fundamentais ao processo de ensino. Pimenta (2015) ainda afirma que a formação de professores em docência no ensino superior deve, na atualidade, ser revestida da prática pedagógica, pois, num contexto dinâmico que a sociedade vive em pleno século XXI, há que se admitir a grande lacuna que a falta da Didática ainda persegue a formação docente nesse nível de ensino. Sob esse aspecto Pimenta (1993) afirma que:

O exercício da profissão de professor requer preparo. Ser professor não é tarefa simples. Entendemos que essa preparação se dá tanto ao nível da formação em instituições e cursos especializados, quanto no processo de exercício direto da atividade profissional nas escolas, nas associações profissionais, enfim, na prática do exercício profissional. Embora tendo funções específicas, essas instâncias da formação não são dissociadas. Os cursos de formação devem ter a prática 
profissional como ponto de partida e essa, por sua vez, deve se alimentar das reflexões realizadas nos cursos de formação (PIMENTA, 1993, p. 128).

É necessário pensar, então, um processo formativo que desenvolva o trabalho pedagógico dos professores universitários pautado em questões Didáticas que articulem a práxis ${ }^{2}$. É salutar que os professores universitários compreendam o seu papel como agentes de transformação sistêmica no processo de ensino e aprendizagem frente aos discentes e a essa transformação, a Didática pode sim contribuir para a superação de afeto transacional nas relações entre professores e alunos em tempos adversos como esse.

\section{CONSIDERAÇÕES FINAIS}

Neste estudo, apresentamos nossas reflexões sobre os novos desafios à formação de professores em tempos de isolamento social. Para tanto, a Pedagogia Universitária é convidada a se manifestar sobre os tempos de pandemia em que ela se pegou e como pode superar os embates que o vírus impôs em toda a sua estrutura.

Nesse contexto, a construção da identidade docente ganha mais um capítulo no atual cenário, onde os professores enfrentam os desafios de atuarem em caráter remoto e contar com o suporte da instituição ao qual estão vinculados, se torna o diferencial para as atividades laborais.

As práticas pedagógicas se ampliam à medida em que a mudança das aulas presenciais para as conectadas ganha novo sentido. Dessa forma, a Didática também se realinha para atender a uma nova realidade e demanda ímpar em que o desempenho profissional docente deve se estabelecer.

À guisa de conclusão refletimos que independentemente do formato das aulas, o eixo central da Pedagogia Universitária que é a formação de professores, continua sendo de vital importância e necessidade de valorização da profissão, pois a mediação do professor no processo de ensino e aprendizagem influi diretamente para a formação e profissão dos alunos.

\section{REFERÊNCIAS}

ALMEIDA, Maria Isabel. Desenvolvimento Profissional Docente: uma atribuição que também é do sindicato. Reuniões Científicas. Trabalho. GT04-Didática. 23ª Reunião Nacional da Anped. Caxambu, MG: ANPED, 2000. Disponível em http://23reuniao.anped.org.br/textos/0412t.PDF. Acesso em 20 jan. 2020.

ALMEIDA, Maria Isabel; PIMENTA, Selma Garrido. A construção da pedagogia universitária no âmbito da Universidade de São Paulo. In: PIMENTA, Selma Garrido; ALMEIDA, Maria Isabel. (orgs.). Pedagogia Universitária: caminho para a formação de professores. São Paulo: Cortez, 2011.

BOLFER, Maura Maria Morais de Oliveira. Reflexões sobre prática docente: estudo de caso sobre formação continuada de professores universitários. 2008. 238 f. Tese. (Doutorado em Educação) - Faculdade de Educação, Universidade Metodista de Piracicaba, São Paulo, 2008. Disponível em https://www.unimep.br/phpg/bibdig/pdfs/2006/LWFMJKHNXBBS.pdf.Acesso em 19 out. 2019.

BROILO, Cecília Luiza. Con(formando) o trabalho docente: a ação pedagógica na universidade. 2004. 267 f. Tese (Doutorado em Educação) - Faculdade de Educação, Universidade Federal do Rio Grande do Sul, Porto Alegre, 2004. Disponível em

${ }^{2}$ Unidade teoria e prática (PIMENTA; LIMA, 2017, p. 33). 
DOI: $10.12957 /$ teias.2021.54019

https://www.lume.ufrgs.br/bitstream/handle/10183/4971/000417875.pdf?sequence=1\&isAllo wed $=$ y. Acesso em 22 jan. 2020.

DAY, Christopher. Desenvolvimento profissional de professores: os desafios da aprendizagem permanente. Colecção Currículo, Políticas e Práticas, n. 7. Porto: Porto Editora, 2001.

FLORES, Maria Assunção; SIMÃO, Ana Margarida Veiga. (org.). Aprendizagem e desenvolvimento profissional de professores: contextos e perspectivas. Edições Pedago: Portugal, 2005.

FORMOSINHO, João. Formação de Professores: Aprendizagem profissional e acção docente. Porto - Portugal: Porto Editora, 2009.

LIBÂNEO, José Carlos. Didática. 2. ed. São Paulo: Cortez, 2013.

MELO, Geovana Ferreira; CAMPOS, Vanessa. T. Bueno. Pedagogia Universitária: por uma política institucional de desenvolvimento docente. Cadernos de Pesquisa. São Paulo, v. 49, n. 173, p. 44-63, jul./set. 2019b. https://doi.org/10.1590/198053145897. Disponível em

http://publicacoes.fcc.org.br/ojs/index.php/cp/article/view/5897. Acesso em 16 out. 2019.

PIMENTA, Selma Garrido. A didática na licenciatura. Rev. Fac. Educ., São Paulo, v. 19, n. 1, jun. p. 128-132. 1993. Disponível em

http://educa.fcc.org.br/scielo.php?script=sci_arttext\&pid=S0102-

25551993000100013\&lng=pt\&nrm=iso. Acesso em 9 mar. 2018.

PIMENTA, Selma Garrido. Formação de professores: identidade e saberes da docência. In:

PIMENTA, Selma Garrido. (org.). Saberes pedagógicos e atividade docente. São Paulo: Cortez Editora, 1999. p. 15-34. Disponível em

https://edisciplinas.usp.br/pluginfile.php/4404301/mod resource/content/3/Texto\%20Pimenta- \%201999-FP-\%20ID\%20\%20e\%20SD.pdf. Acesso em 23 fev. 2019.

PIMENTA, Selma Garrido. Formação de Professores: identidades e saberes na docência. In: Selma Garrido Pimenta. (org.). Saberes pedagógicos e atividade docente. 4. ed. São Paulo: Cortez Editora, 2005.

PIMENTA, Selma Garrido. Formação e Profissionalização docente. Entrevista concedida ao Programa de Pós-Graduação em Educação da Universidade Católica de Santos - UNISANTOS, SP. Programa Urbanidades UNIS ANTOS. Santos: São Paulo, 2015. Disponível em https://www.youtube.com/watch?v=outmfB7-hzI. Acesso em 20 ago. 2018.

PIMENTA, Selma Garrido; ALMEIDA, Maria Isabel. (orgs.). Pedagogia Universitária: caminho para a formação de professores. São Paulo: Cortez, 2011.

PIMENTA, Selma Garrido; ANASTASIOU, Léa das Graças Camargos. A Docência no Ensino Superior. 5. ed. São Paulo: Cortez, 2014. 


\section{Informações do autor}

Gean Breda Queiros

Universidade Católica de Santos

E-mail: geanbreda@hotmail.com

ORCID: http:// orcid.org/0000-0003-0242-773X

Link Lattes: http://lattes.cnpq.br/9520588940694258 